\title{
Analyzing How to Build the Bridge Between the Chinese Collection and Western Audiences from the Different Thinking Mode
}

\author{
Jingyi Peng \\ Business Administration, Art Management, Gachon University, Seongnam, Korea
}

\begin{abstract}
The origin of Chinese traditional culture can be traced back to 5000-7000 years ago, which has a long history. Throughout the history, we can see that the reason why Chinese traditional culture can become the only endless culture in the world is, basically, that Chinese traditional culture has strong innovation ability and contain the great wisdom of humanity [1]. With the development of globalization and technology, China and Chinese culture are facing a new situation, which is breaking the culture barrier and spreading Chinese culture to the west, and it is also a challenge [2]. In the field of contemporary curation, the main concentration is how to build the bridge between Chinese traditional collections and Western audiences, and crossing the two different culture background to understand and unscramble. The research article focuses on analysis the factor of western audiences understanding barriers, and discussion how Chinese collections to connect with western audience better.
\end{abstract}

Keywords: Cross-culture, Exhibition, Thinking mode.

\section{Introduction}

Cultural globalization refers to the phenomenon that, under the background of globalization, the cultures form different countries merge and collide with each other, and break the restrictions of national boundaries. The rise and development of cultural globalization is an objective trend, which not only brings vitality to Chinese traditional culture, but also brings challenges to the development of Chinese traditional culture. With the development and deepening of globalization, cultural exchanges between China and the world getting closer. As an ancient cultural country with 5,000 years, Chinese history and culture are not only the essence of the Chinese nation's culture, but also an indispensable part in the world.

When this trend comes to the curation, exhibitions are one of the main channels for spreading world culture and an essential part in art world today. The exhibits are effectively expressed through the visual presentation in the exhibition hall, and the audience appreciates according to the logic under the guidance and arrangement from the curator. At this time, the exhibition is not only a tool for presenting collections or a medium for cultural communication, but also contain cultural significance and academic value [3].

However, the development of cultural globalization is not formed in a short period of time, it is a long process of formation, including blend and collisions, and the development of cultural globalization cannot eliminate the inherent differences between various cultures. Due to the gaps in cultural understanding caused by differences in Chinese and Western cultures, languages, habits, and so on, Western audiences usually have problems in their interpretation of Chinese culture and collections. How to correctly represent Chinese traditional culture and make western audiences resonate with it is the concentration for curators. Through the language and approach of the exhibition, how the curator reinterprets traditional Chinese culture to Western audiences is a worthy study. This problem be faced with spreading Chinese culture in the Western world.

Based on previous research and curatorial cases, this research will analyze and explore the main difficulty about connection between the Chinese culture and western audiences in the exhibition, and propose strategies. The article is mainly divided into three parts. The first part will analyze the differences in thinking mode between Western and Chinese, which will lay the foundation for the next part research that key barrier in the interpretation of Chinese culture. The second part is to research and analyze how to represent Chinese cultural to the western audience in the exhibition, which points out the direction for the third part the curatorial approach. In the third part, discussing strategy that promote understanding of Western audiences to Chinese in the exhibition. It is hoped that through this research, it can provide a reference for the spreading Chinese cultural in exhibitions for the West, and promote the Chinese culture exchanges between the two sides.

\section{The Difference Thinking Mode between the Western and Chinese}

\subsection{Causal Thinking and Relevant Thinking}

From the perspective of western philosophy, Hao Dawei and An Lezhe believe that the Western thinking mode is causal thinking, and that the change is influenced and ultimately determined by motivations. The causal thinking in the Western world is also the dominant in the classical western society. For example, it is in the Bible attributing the origin of the world to separation from the 'chaotic world', or believing that the cosmic order is caused by the result of the soul, the creator, the first mover, the will of God, and so on. These explanations always reflect the relationship between cause and effect[4]. In contrast, the Eastern thinking mode is 
inclined to related thinking. This thinking mode recognizes that change or process is static and immutability, and it seeks to explain the state of things in terms of related processes, rather than the motives or principles.

\subsection{Circular Thinking and Linear Thinking}

The thinking mode differences between Chinese and Westerners can also be divided into circular thinking and linear thinking. Chinese society is dominated by circular thinking, while Westerners are dominated by linear thinking. When Chinese people state facts, they often do not directly state their position. They tend to descript the side as the starting point, gradually advance, and finally introduce key points. [4] This thinking mode is inseparable from the autocratic monarchy system in ancient China that has been implemented for more than 2,000 years. Correspondingly, it forms the central thinking for Chinese. The central right and power are absolute authority. Everything has to revolve around the central government and the emperor, which make the thinking path of the Chinese show a spiral development trend. As far as the West is concerned, in the process of exploring nature and society, it is mainly linear thinking mode. For example, not only Euclid's geometry is straight. Aristotle's logic also is linear. This laid the cultural foundation for the linear thinking to Westerners. They through the idea or logical structure, make it is communicable, so that everyone can decide its choice according to the universally recognized standard [5].

\subsection{Concrete Thinking and Abstract Thinking}

Also, the Chinese mainly think in images, while the Westerners tend to abstract. The formation of concrete thinking and abstract thinking are both closely related to social development. On the one hand, the Chinese thinking mode is comprehensive and specific. Since ancient times, logic has been underdeveloped in China, not good at rational analysis and logical thinking, also the level of abstraction is very low. Descriptions of objective things are often accustomed to analogical reasoning or depend on first intuition. Then use a variety of specific comparisons and image meanings to elaborate [6]. On the contrast, for the West, abstract thinking is formed along with its continuous exploration in nature and society. The observation and exploration of objective things in Western thinking mode tend to logic and experimental methods. Logic makes the concept definite, and experiment makes the concept have a mathematically quantitative formula, and there are finally standards for judging correctness and error.

\section{The Key Problem of Representing Chinese Culture to the Western Audience in the Exhibition}

\subsection{Building Comprehensive and Compete Background Knowledge}

The cross-cultural exhibitions usually involve cooperation between China and the West. The Chinese side usually provides cultural collections and guidance, while the West provides venues and overall planning. In the process of cooperation, due to the series of barriers, museum staff not familiar with the Chinese culture background, difficult to obtain information about Chinese culture, the language exchange between China and the West not smooth, the information sharing system immature, the time tight and so on. The western curator is hardly to interpretate Chinese culture and collection deeply, so that information cannot be to establish to the systematic background knowledge for the audience, and even the display content is out of touch with the theme. Due to the far distance between the two countries, the culture backgrounds, customs, and religious beliefs in the two countries are different. How to connect Western audiences with Chinese culture and collection is a key breakthrough. Therefore, the foundation and supplement of the relevant knowledge background in the venue is particularly important. Without comprehensive background knowledge as auxiliary materials for viewing, the audience not only cannot understand the connections and differences between cultural relics, but also innocent with the cultural phenomena behind them. This browsing staying on the visual surface cannot achieve the fundamental purpose of cultural dissemination and communication. Therefore, the first step in interpreting Chinese culture and collections is to build a comprehensive and complete background knowledge.

\subsection{Showing in the Western Thinking Mode}

After building a comprehensive and complete background knowledge, the key to the next step is how to effectively disseminate background information and cultural information to Western audiences. Many museums holding cross-cultural exhibitions mainly rely on the way that direct "translating" relevant Chinese materials to explain. This leads to foreign cultures that are difficult to be understood and appreciated by Western audiences. Due to differences in thinking, they cannot understand in a broader and deeper level.

From the perspective of communication science, the information sender is the exhibition, and the receiver is the audience. How to improve the efficiency for information reception, should be considered on the audience cognition in the start, and put forward more possibilities for exhibition showing. According to the analysis of the differences between Chinese and Western cognitive thinking, it is found that Western cognitive thinking has strong characteristics, such as causal, logical, and linear. Therefore, when describing and expressing related stories and collections, a logical and contextual approach is used to provide Western audiences with a better understanding.

\subsection{Stimulating Audience Interest and Cultural Resonance in the Interesting Way}

After comprehensively establishing a channel for dissemination of Chinese collection to Western audiences, enhancing the visiting experience and interest is another issue that curators need to think about. Due to the lack of learning to related background knowledge in advance, and the audience 
is likely to be less interested in cross-cultural exhibitions. At the same time, due to the simplification of interpretation way and the lack of environment creation and design. Even exhibitions with many rare and precious treasures cannot bring a good sense of experience to the audience, and it is more difficult to stimulate the interest of audiences in learning, which hinders the audience from understanding foreign cultures. Incorporating interesting interactions and diversified presentation methods in the exhibition, and through the design and arrangement of storyline, to bring a viewing experience with both entertainment and academic value.

\section{The Curation Approach in the Exhibition}

\subsection{Connection with Daily Life}

For a considerable part of the audience in the museum, the museum adds some content that is closer to life in the exhibition, which can more arouse their interest in the exhibition. Therefore, except the textbook-style explanation in the label, exhibition planning also needs to integrate the knowledge with interesting point and life element, which increase the sense of participation in the visit. So as to form a multi-dimensional and multi-level interpretation system to meet the diverse and personalized needs in exhibition.

In 2013, the Asian art announced on social media that a terracotta warrior was lost on the way to San Francisco in San Jose, south of San Francisco. The terracotta warriors who left the team wandered around, unable to find the direction to return to the team. Therefore, the museum released this story in the hope that the public can help the lost terracotta warriors return to the museum. In fact, this is an event planned by the Asian Art Museum and invited actors to play the terracotta warriors, as shown in Figure 1.

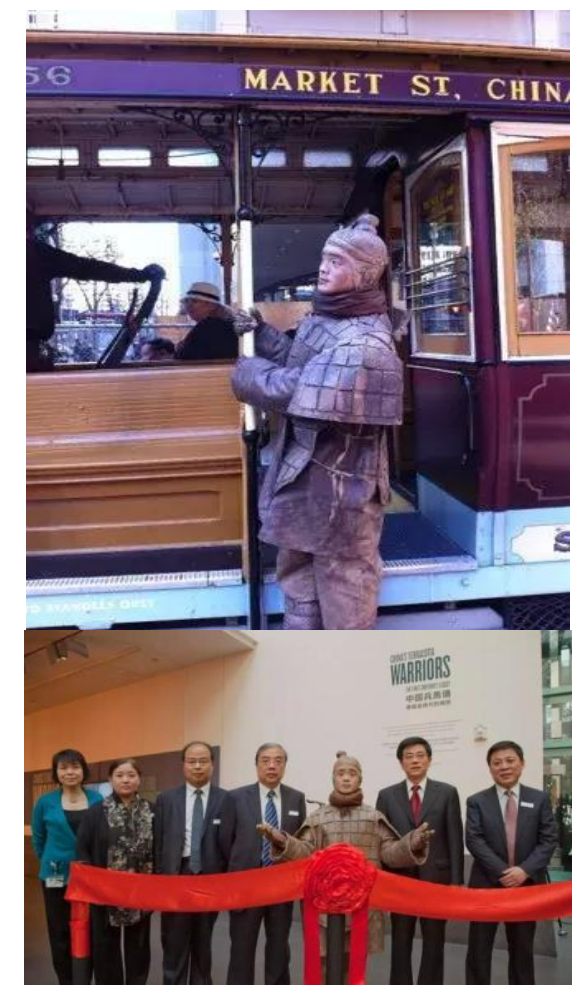

Figure 1: An actor to be dressed as a living terracotta warrior [8]
There are two purposes of the activity. One is to draw the distance between the audience and the unfamiliar terracotta warriors through the activity, increasing the audience's sense of participation, establishing a connection with the terracotta warriors, and arousing the audience's interest. The second purpose is to promote the popularity of Asian Art Museum. If the audience wants to help the lost terracotta warriors return to the Asian Art Museum, they should first know where the Asian Art Museum is, so as to promote the popularity of the Asian Art Museum. This kind of interactive activity is fun and allows people to participate voluntarily, making the audience eager to actively learn about the culture of the Terracotta Warriors. The scene of San Francisco and nearby areas participating in this interactive activity, which connects the unfamiliar culture with the life scene around the audience and helps the audience to resonate with Chinese culture. When the audience immersed themselves in it and learned some relevant background early in the interactive process, they could better appreciate the cultural collections in the exhibition.

\subsection{Showing Exhibition in Western Context.}

Chen Danqing, a Chinese scholar in Arts, once mentioned an opinion in the program "Parts" that the appreciating the painting, from the wall where the painting is displayed, the exhibition hall, and the museum, to the city, country, and street where the museum is located, all affect the temperament of the art. Although the above point of view is a discussion for the artworks in history, it also inspires museum exhibitions and cross-cultural interpretation from another aspect, reminding how the context important to the meaning expressed by collections. The exhibition context usually makes use of the scenes presented, which replicate scenes and combinate collections to create a "small space" for the audience, and help them to recognize and understand. However, for cross-cultural exhibitions, traditional Chinese culture is shown in the West. The focus is that combine the cultural background and cognitive habits of Western audiences to create a new context for them. It promotes audience to study, judge and pay attention to the artistic and ideological value behind the cultural collection. The process of creating context is not to spoon-feed culture into the audience, but arouse the audience's interest in learning and communication through the clever use of language, text, and sense. In 2017, Age of Empires: Chinese Art of Qin \& Han Dynasties held at the Metropolitan Museum. The "Age of Empires" in the title is very eye-catching, and the term "Empire" is not commonly in the Chinese cultural concept, but this choice is result of considering Western culture. The curator Sun Zhixin believes that holding exhibitions in West, it is necessary to consider Western audiences, particularly their knowledge and cultural background. Western audiences may be familiar with ancient Western history, such as Greece and Rome, but they are quite unfamiliar with ancient Qin and Han dynasties, including general Chinese history and culture. The interpretation of the Chinese history into the world civilization framework helps the western audience to compare and understand. The content of Sino-foreign cultural exchanges displayed in the exhibition, especially the cultural connection and interaction between the Qin Han Dynasties and Greco-Roman, narrowed the distance between the 
audience and the exhibition. China in the Qin and Han Dynasties is no longer a far distant and unfamiliar existence, but inextricably link to Western world, and it is an important part of the entire world [10]. Hence, the title involves 'Empires', the purpose is to make Western audiences connect to the ancient Greek and Roman Empire, which is of great significance to Western civilization, through the word "Empire", analogize the mysterious Eastern civilization in familiar concepts and contexts. And then realize the cultural context. Creating and integrating exhibition context achieve the effect for eliminating cultural barriers.

\subsection{Finding out the Same Point between West and East.}

For cross-cultural exhibitions, the biggest obstacle for western audiences is the difference in knowledge concepts and thinking mode. Chinese thinking mode in images is accustomed to feel things, and then use image analogy to express concretely. This way of thinking also determines that Chinese characters are hieroglyphs, and the shape of the characters comes from nature. Pursuit for writing art for thousands of years in China, a unique artistic genre of calligraphy has been formed. Ancient Chinese calligraphy, as the peak of Chinese art, originated from the understanding of shapes and image. Nowadays, people can still appreciate the beauty and splendor of nature in calligraphy works. This kind of thinking mode and concept is completely isolated from the Western art, which is difficult point for Western audiences to interpret. In 2013, the Asian Art Museum curated the exhibition about Chinese calligraphy, named "Out of character: Decoding Chinese calligraphy ", which provide the new curatorial way for the Chinese calligraphy art. The ancient artist Wen Peng's thousand-character calligraphy is displayed in the form of installation art for the western audience understanding better. Through Western audiences' familiar knowledge in installation art, connecting their aesthetics to the calligraphy art, shown in as figure 2 . This innovative form connects western contemporary art and Chinese traditional art to be easier for Western audiences to understand. In addition, the connection between Chinese calligraphy and the West is abstract expressionism. Although these are two completely different art genres, their expression methods are common, and they both emphasize internal expression. This approach makes use of a familiar art form to guide western audiences learning an unfamiliar art form, which can be look at as a translator, a kind of tool that helps western audiences transform western culture into the eastern culture. For the western audience, the key to western audiences willing to visit the Chinese traditional exhibition is that connect the unfamiliar culture with their own culture or the familiar things around them. This way can not only help them understand the different culture easier, but also have the motivation to visit. Background knowledge is the basic condition for understanding exhibitions. This approach uses the basic knowledge of contemporary art to trigger western audiences' interest and the sense of resonance to Chinese art. Also, holding interesting activities and cultivate interest, which can stimulate to the senses for fresh things or content, and enhances their interest in learning by inspiring the western audience curiosity about new things in interactive activities.

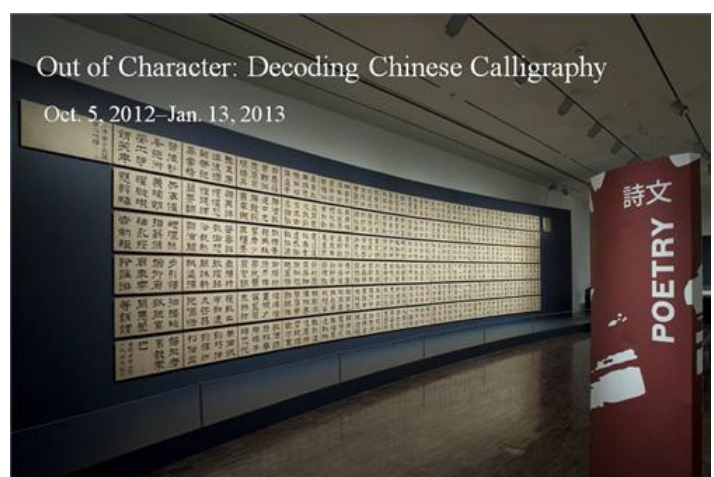

Figure 2: Wen Peng's thousand-character calligraphy [11]

\section{Conclusion}

Chinese culture is ancient and mysterious, which makes the world curious about it, and has the desire to explore. The cultural system, background, and thinking mode that are different from the Western mainstream, also set up barriers for Western audiences to enter Chinese culture. The bridge connecting the two parties not only requires comprehensive and complete background knowledge and cultural collections display that meets the visual aesthetics, but also needs to consider the thinking style, customs, and cultural systems of Western audiences. Also, make the use of interactive activities to enhances the participation of Western audiences, arouses in-depth thinking about Chinese culture.

\section{References}

[1] Fan, Y. (2000). A classification of Chinese culture. Cross Cultural Management: An International Journal, 7(2), 3-10.

[2] Weller, R. P. (2006). Discovering Nature: Globalization and environmental culture in China and Taiwan. Cambridge University Press.

[3] Cai, T. \& Sun, Q. (2009) Cultural Globalization from the Perspective of Constructivism - Computation between Chinese Traditional Culture $[\mathrm{J}]$. Nankai Journal: Philosophy and Social Science Edition (6): 79-85.

[4] Wang, S.R.\& Yu, B.L. (1996) Theory and Icon Thinking. China Social Science.

[5] Liu, C.L. (1985) On the philosophical nature of information. China Social Science.

[6] Liu, R. (2010) Differences in the Mid-West Thinking Mode and Its Causes [J].

[7] Hou, Y.B. (2003) Viewing the difference in the East Western culture from thinking $[\mathrm{N}]$. Bright Daily. 2003-1-14.

[8] Yang, S. (2018) An actor to be dressed as a living terracotta warrior [online] available from<http://www.sohu.com/a/284372679_428290> [Accessed 11 March 2011]

[9] Zhang, J.H. (2012) Review of the Exhibition Work of the US Bao Museum. Beijing Yanshan Publishing House.

[10] Xu, J. (2015). Wen Peng's thousand-character calligraphy [online] available from<https://video.artron.net/c4270.html> [Accessed 11 March 2011] 